\title{
Article \\ Collision Risk Assessment Support System for MASS RO and VTSO Support in Multi-Ship Environment of Vessel Traffic Service Area
}

\author{
Yunja Yoo ${ }^{1}\left(\mathbb{D}\right.$ and Jin-Suk Lee ${ }^{2, *(1)}$ \\ Maritime Safety Department, Korea Maritime Institute, Busan 49111, Korea; yjyoo@kmou.ac.kr \\ 2 Division of Navigation Science, Mokpo National Maritime University, Mokpo 58628, Korea \\ * Correspondence: jslee@mmu.ac.kr
}

check for

updates

Citation: Yoo, Y.; Lee, J.-S. Collision Risk Assessment Support System for MASS RO and VTSO Support in Multi-Ship Environment of Vessel Traffic Service Area. J. Mar. Sci. Eng. 2021, 9, 1143. https://doi.org/ 10.3390/jmse9101143

Received: 13 September 2021

Accepted: 15 October 2021

Published: 18 October 2021

Publisher's Note: MDPI stays neutral with regard to jurisdictional claims in published maps and institutional affiliations.

Copyright: (c) 2021 by the authors. Licensee MDPI, Basel, Switzerland. This article is an open access article distributed under the terms and conditions of the Creative Commons Attribution (CC BY) license (https:/ / creativecommons.org/licenses/by/ $4.0 /)$.

\begin{abstract}
The discussions by the International Maritime Organization for the introduction of a maritime autonomous surface ship (MASS) began in earnest. At the 27th ENAV meeting, the International Association of Marine Aids to Navigation and Lighthouse Authorities proposed the "sharing of a common operating picture for situational awareness of the waterway within vessel traffic service (VTS) environment" when developing a system to support MASS operation. Marine accidents caused by collisions on waterways still account for a high percentage of ship accidents that occur at sea, and many studies have investigated the risk of collision between ships. Collision risk assessment was primarily conducted in ship domain-based safety areas. This study evaluates the collision risk using the ship domain derived by the VTS operator (VTSO) and proposes a real-time collision risk assessment support system to improve the situational awareness of VTSOs and MASS remote operators (MASS ROs) regarding near-collision situations occurring in local waters. To evaluate the validity of the proposed system, a risk analysis was performed on near-collision scenarios at Busan Port. The results show that the distance to the closest point of approach (CPA), time to the CPA, and inter-ship distance converged within 0.5 nautical miles, $10 \mathrm{~min}$, and 3 nautical miles, respectively.
\end{abstract}

Keywords: ship collision; risk assessment; maritime autonomous surface ship (MASS); remote operator (RO); vessel traffic service operator (VTSO); collision risk assessment support system

\section{Introduction}

The International Maritime Organization (IMO) included discussions of maritime autonomous surface ships (MASSs) in the official agenda of the 99th meeting of the Maritime Safety Committee (MSC) in 2018, and they have prepared a regulatory scoping exercise (RSE) for MASS operation [1-6]. The discussions have defined MASS vessels for RSE work and categorized their autonomy level (degree one: ship with automated processes and decision support; degree two: remotely controlled ship with seafarers on board; degree three: remotely controlled ship without seafarers on board; degree four: fully autonomous ship) [1]. The autonomy level of MASSs is divided into levels 1 and 2, in which a crew is on board, and levels 3 and 4, in which no crew is on board. Levels 2 and 3 represent the concept of a remote operator (RO), which remotely controls a MASS vessel from the remote control center (RCC) on shore. Remote operation requires the development of collision risk assessment technology to determine the MASS collision risk at sea.

The International Association of Marine Aids to Navigation and Lighthouse Authorities (IALA) has been discussing its support of MASS operations at each stage of the IMO discussions on the relevant agreements for MASS operations. The Draft MASS Guideline was submitted at the 27th meeting of the e-Navigation Information Services and Communications (ENAV) committee for the implementation and testing of MASS systems following the introduction of MASSs, and nine prior considerations were proposed to provide system guidance to support MASS operations $[7,8]$. The document contains points related to the 
"sharing of a common operating picture for situational awareness of the waterway within vessel traffic services (VTS) environment" and "scoping and development of guidance on the interaction between VTS and the control for MASS shore control center (SCC)," among the prior considerations of MASS system guidance. In many cases, because the lack of situational awareness leads to an accident due to human error, situational awareness in dangerous waters could help prevent accidents [9-14]. Therefore, when implementing a system for the situational awareness of collision risks in VTS areas and the interaction between MASSs and VTS centers, collision risk assessment and support technologies for VTS operators (VTSOs) and ROs in multi-ship encounter situations in VTS areas must be implemented in a real-time system as a key module.

Fujii and Tanaka, 1971 [15] proposed the concept of an empirical ship domain model to evaluate the risk of collision based on the ship encounter situation at sea. Subsequently, a ship operator survey and an empirical ship domain model based on RADAR and AIS data were introduced by Coldwell, 1983 [16], Goodwin, 1975 [17], Hansen et al., 2013 [18], and Wang and Chin, 2016 [19]. In addition, various ship domain models based on expert knowledge, computer simulation, neural networks, fuzzy neural networks, analytical traffic, multi-ship conflict complexity, and safety analysis were proposed to evaluate the risk of ship collisions [20-29]. This ship domain-based risk assessment determines whether the domains of one's own ship and other ships invade each other at the current location; however, the method is limited because the risk of a collision at the closest point of approach (CPA) location could not be evaluated in advance if the current voyage continued. Therefore, Yoo and Lee, 2019 [30] proposed a collision risk index (CoRI) model based on the concept of the ship domain at the CPA to calculate the subjective collision risk from the perspective of a VTSO for ship collisions in VTS areas depending on the distance to collision, time to collision, and encounter attitude risk between ships. The ship collision risk determined by the CoRI model is similar to that determined by an RO that remotely controls MASS vessels because both assess possible ship collision risk situations in the VTS control center via a VTSO.

The collision alert system (CAS), which can evaluate real-time risk situations in multi-ship environments, is known to improve the VTSO's situational awareness of local waters [31,32], and the CAS system generates a warning alarm when the distance to the CPA (DCPA) and time to the CPA (TCPA) are below the set value [32-36]. In addition, studies related to CAS systems include heuristic criteria to evaluate the collision risk, which was proposed by Patraiko et al., 2010, Hilgert and Baldauf, 1997, and Baldauf et al., 2011 [37-39], fuzzy systems proposed by Bukhari et al., 2013, Kao et al., 2007, and Ren et al., 2011 [40-42], quantitative risk assessment applied dynamic adjustment by Mou et al., 2010 [43], and CAS regression modeling by Chin and Debnath, 2009 [33]. In addition, Baldauf and Fischer, 2019 conducted a simulation experiment that assumes a preliminary situation wherein MASS ships and existing ships operate in common in the VTS area, and they compare the actions taken by groups with and without navigation experience against collision risk situations [44]. In this experiment, the authors derived issues (such as the qualification and training of the RO, existing systems that should be further updated for the RO's situation awareness, etc.) that should be reflected in the future CAS system for the situation awareness of the ROs.

The purpose of this study is to develop a real-time collision risk assessment support system that provides the VTSO and MASS RO with related graphic information and quantitative data on the risk situations in local waters in the event of a near-collision situation in the VTS area where multiple ships navigate. To this end, the safety area ship domain model by the VTSO provides a CoRI risk value according to the ship encounter situation of multiple ships to improve the situational awareness of local waters by generating an alarm in the event of a near-collision situation. Section 2 describes the CoRI model and risk assessment method, and Section 3 presents the results of the collision risk analysis for near-collision scenarios. Section 4 proposes a risk assessment algorithm and a collision risk assessment support system (RiASS) configuration for VTSO and MASS RO situational 
awareness in a multi-ship environment. Finally, Section 5 summarizes the limitations and key points of this study.

\section{Methodology}

A collision risk assessment module is proposed to evaluate the collision risk caused by multi-ship environments in the VTS area, and support VTSO and RO control and remote evacuation. The module is based on the number of combination cases within the minimum separation distance between ships $i$ and $j$, and it sends an alarm to the VTSO and RO systems if the collision risk index output exceeds the set value. The collision risk models and methodologies to evaluate the collision risk in multi-ship environments are described in the following subsections.

\subsection{Collision Risk Model}

Based on the ship domain at the CPA position, the CoRI model, in which the VTSO assesses the risk of collision for ship encounters at sea, yields risk indices according to the inter-ship encounter, and it finally estimates the value of the CoRI that reflects the risk attitude of the VTSO.

The encounter risk $E_{i j}$ between ship- $i$ and ship- $j$ is expressed as follows in the head-on, crossing, and overtaking scenarios for the two vessels:

$$
\begin{gathered}
E_{i j}=R_{c p a}\left(\theta_{i}\right)+R_{c p a}\left(\theta_{j}\right) \\
R_{c p a c p a}^{i j}\left(\theta_{i j}\right)= \begin{cases}a \operatorname{sech}(d \theta) & \text { if } 0 \leq \theta<\frac{2 \pi}{3} \\
b \operatorname{sech}(e(\theta-\pi)) & , \text { elseif } \frac{2 \pi}{3} \leq \theta<\frac{3 \pi}{2} \\
c \operatorname{sech}(f(\theta-2 \pi)) & , \text { else } \frac{3}{2} \leq \theta<2 \pi\end{cases}
\end{gathered}
$$

Here, $R_{c p a}^{i j}$ is the encounter risk according to the relative bearing $\theta_{i, j}$ from ship-i,j; $a, b$, and $c$ are the coefficients determined by the bow or stern maximum risk value of the ship; and $d, e$, and $f$ are the coefficients determined by the risk level of the encounter situation.

The risk $A_{i j}$ according to ship-to-ship proximity is expressed as an index that quantitatively represents the proximity risk of the target ship using the safety distance $D s_{i j}$ of the ship domain at the CPA position and the proximity index $R_{s d}$, which indicates the proximity of the ship:

$$
\begin{gathered}
A_{i j}=R_{s d}^{i}(l)+R_{s d}^{j}(l) \\
R_{s d}\left(f_{i j}\right)=\operatorname{sech}\left(g \cdot f_{i j}\right) \\
f_{i j}=\mathrm{DCPA} \cdot D s_{i j}^{-1}
\end{gathered}
$$

Here, $R_{s d}$ is the approaching risk index from ship- $i, j$ considering the safety domain, $g$ is the coefficient determined by the risk level in the VTSO domain, $f_{i j}$ is the approaching factor based on the DCPA and VTSO domain for ship- $i, j$ at the CPA position, and $D s_{i j}$ is the safety distance from the CPA to VTSO domain intersection for ship- $i, j$.

The hazard of ship-to-ship proximity $T_{i j}$ is an index that quantitatively represents the proximity hazard of ship- $i$ and ship- $j$, and it considers the effect of each factor that constitutes the ship's specifications on the time remaining until the collision.

$$
\begin{gathered}
T_{i j}=R_{a t}^{i}(\tau)+R_{a t}^{j}(\tau) \\
R_{a t}^{i j}(\tau)= \begin{cases}\operatorname{sech}(h \tau) & \text {,if } \tau \geq 0 \\
\operatorname{sech}(k t) & , \text { else } \tau<0\end{cases} \\
\tau_{i j}=\tau_{\text {min }} \cdot\left(1-\frac{I_{\text {type }}^{i j}+I_{\text {loa }}^{i j}+I_{\text {beam }}^{i j}+I_{\text {draft }}^{i j}+I_{\text {time }}^{i j}}{100}\right)
\end{gathered}
$$


Here, $R_{a t}^{i j}$ is the risk related to the approaching time from ship-i or ship-j, $h$ and $k$ are the coefficients determined by the VTSO from the time risk value, $\tau_{i j}$ is the time to the collision for ship-i or ship-j, $\tau_{\min }$ is the minimum approach time based on the displacement between the ships, and $I_{\text {type }}^{i j} \cdots, I_{\text {time }}^{i j}$ are the parameters of ship-i or ship- $j$ that affect the time allowance, such as ship type, length, beam, draft, and navigation time.

The collision risk index $R I$ is expressed as the product of the risk indices $E_{i j}, A_{i j}$, and $T_{i j}$, as follows:

$$
\begin{gathered}
R I_{C}(t)=E_{i j} \cdot A_{i j} \cdot T_{i j} \\
\operatorname{CoRI}_{C}(t)=\frac{P_{\max }}{1-\exp (\rho)} \cdot\left[1-\exp \left(-\rho \cdot \frac{-R I(\mathrm{t})}{R I_{\max }}\right)\right]
\end{gathered}
$$

where $R I_{C}$ is the ship collision risk index between the ship-i, $j$ combination at time $t, R I_{\max }$ is the maximum value of the ship collision risk index $\left(R I_{\max }=8\right), P_{\max }$ is the maximum value of the ship collision risk $\left(P_{\max }=6\right)$, and $\rho$ is the VTSO risk attitude. CoRI $I_{C}$ is the collision risk combination between ships $i$ and $j$ in a specific area at time $t$.

\subsection{Collision Risk Assessment}

The International Regulations for Preventing Collisions at Sea (COLREG) Rule 22 states that the minimum sidelight visibility for ships over $50 \mathrm{~m}$ is 3 nautical miles $[45,46]$. Therefore, we propose Risk Assessment (RiAS), which is a collision risk assessment module that yields a CoRI value for all vessel cases within a minimum separation distance of 3 miles for ship-to-ship operations in a multi-ship environment. Additionally, it generates alarms if the reference values set by the VTSO and RO systems are exceeded:

$$
\operatorname{RiAS}_{C}^{i j}(t)=\operatorname{Alarm}_{C}^{i j}(t) \begin{cases}0 & , \text { if } \operatorname{CoR} I_{C}(t)<50 \% \\ 1 & , \text { else } C o R I_{C}(t) \geq 50 \% \text { and } \operatorname{Dist}_{C}^{i j}(t) \leq 3 \mathrm{NM}\end{cases}
$$

where $\operatorname{RiAS}_{C}$ is the collision risk assessment value between the ship-i, $j$ combination at time $t$, Alarm $_{C}$ is the collision risk assessment value between ships $i$ and $j$ at time $t$, which returns a 0 or 1 value if the alarm is off or on, respectively, and Dist $_{C}$ is the distance in nautical miles between ship-i and $j$ at time $t$.

In the event of an alarm in the RiAS module, the VTSO and RO may take action to avoid collisions, including course changes and speed limits. These actions must consider the maneuverability performance and encounter relationships between ships.

Meanwhile, the VTSO risk attitude $\rho$ used in Equation (10) is an attitude of VTSO that can be used to determine the collision risk for situation awareness (or risk situations), and it was derived through a collision risk determination questionnaire for 135 VTSOs working at Korean VTSs in coastal waters [47]. The same value as VTSO risk attitude was applied to $\mathrm{RO}$ risk attitude because the MASS vessel is not yet in the operation stage but from the perspective of controlling ships.

\section{Analytic Results}

The ship traffic data of collision risk situations in the Busan Port VTS area were used to evaluate the collision risk in multi-ship environments for three near-collision (CoRI $\geq 50 \%)$ scenarios [29].

\subsection{Multi-Ship Environment Situation}

The near-collision risk situation used the debriefing system data from the Busan Port VTS on 27 July 2018 [48,49], which lasted for approximately 20 min during the dawn: 05:33:05 to 05:53:35 a.m.

Figure 1 shows the collision risk situation of the Busan Port VTS debriefing system at time 05:50:27. Ship-1, 2, 5, and 6 were entering the port of Busan sequentially, and ship-3, which is a tugboat, was crossing the Busan Port fairway separation zone, thus causing a 
risk of collision with the inbound ships. Therefore, the VTSO was adjusting the entry order and risk situation of the inbound ships.

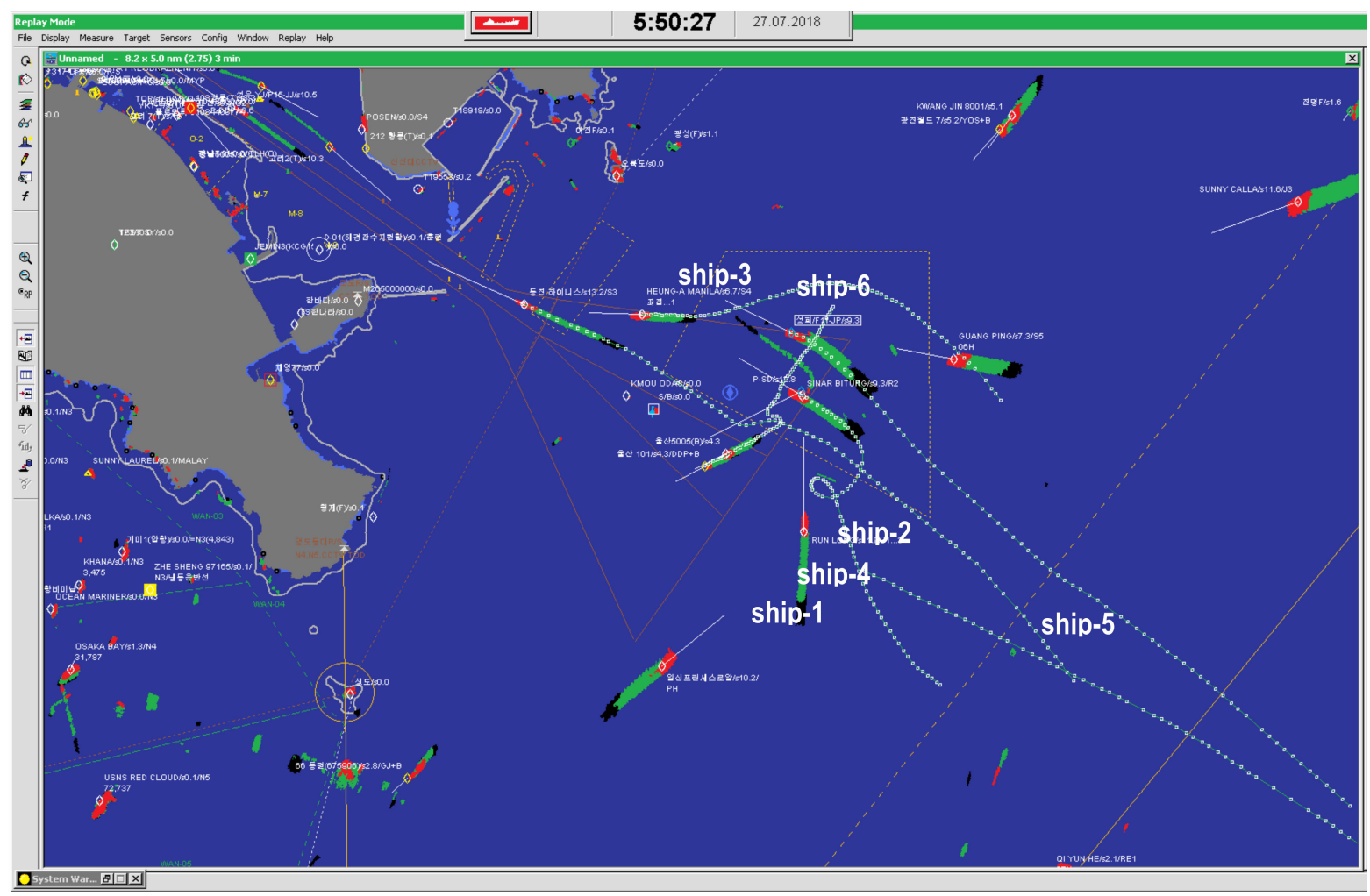

Figure 1. Shows static data from ships 1-6 navigating the VTS area of Busan Port in a collision risk situation. Six multi-ships sailed during that time, with four container ships, one ferry, and a tugboat passing each other. The ship specifications, including length, beam, and draft information, are shown in Table 1.

Table 1. Ship data with dimensions and ship types.

\begin{tabular}{ccccc}
\hline \multirow{2}{*}{ Ship No. } & Ship Type & \multicolumn{3}{c}{ Dimensions [m] } \\
\cline { 3 - 5 } & & Length & Beam & Draft \\
\hline ship-1 & container & 162 & 26 & 5.9 \\
ship-2 & container & 132 & 19 & 6.5 \\
ship-3 & tug & 23 & 6.5 & 2 \\
ship-4 & container & 137 & 25 & 7.9 \\
ship-5 & passenger ship & 162 & 25 & 5.6 \\
ship-6 & container & 142 & 20 & 7.3 \\
\hline
\end{tabular}

\subsection{Collision Risk Analysis Results}

Figure 2 shows the results of plotting the navigation information for ships 1-6 using a 3-min vector during the collision risk situation between 05:33:05 and 05:53:35. At this point, $\bigcirc$ indicates the starting position of the ship-track 3-min vector. The navigation results in Figure 2 show that ship-1 (blue), ship-2 (cyan), ship-5 (magenta), and ship-6 (red) are traveling leftward in the northwest direction, and ship-3 (green) is traveling leftward in the southwest direction. In addition, it can be observed that ship-4 (black) is sailing right from north-west to south-east. 


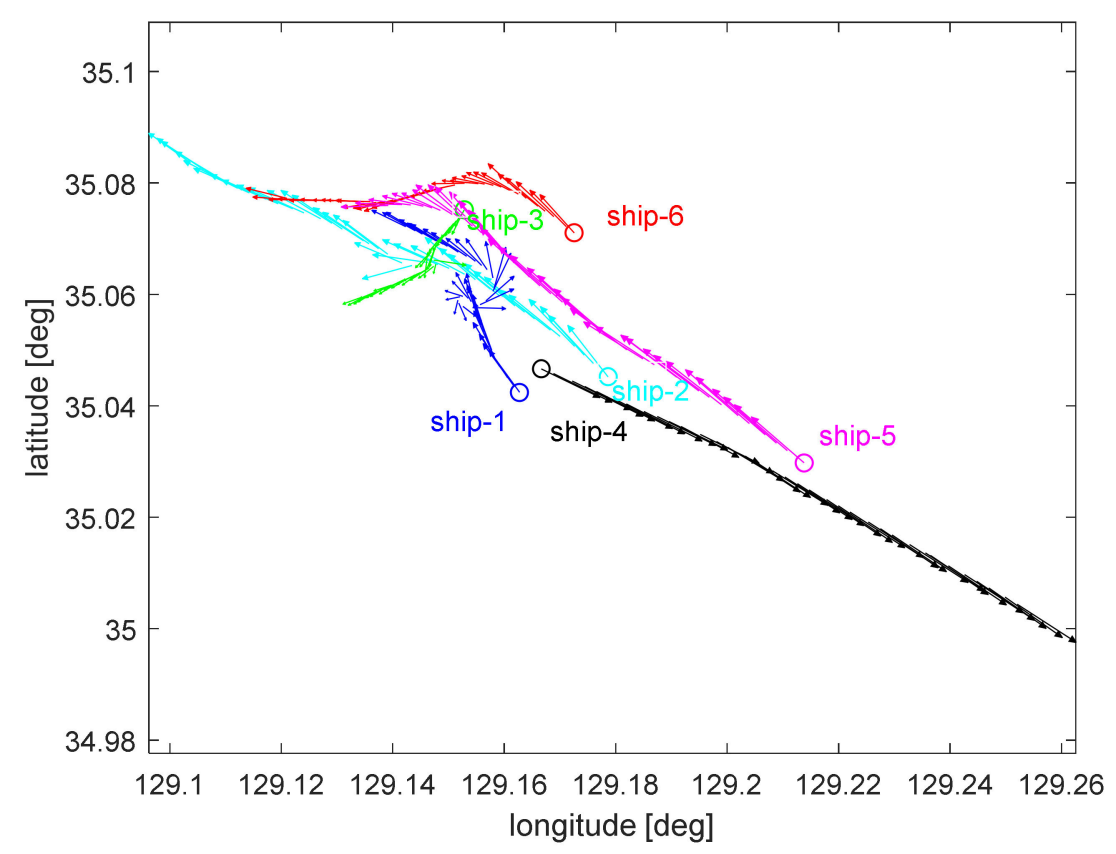

Figure 2. Ship tracks of ships 1-6 with 3-min vectors in a near-collision situation during time 05:33:05-05:53:35 ( $\bigcirc$ : starting position).

For the total number of ships (n) navigating the VTS area in collision risk situations, the combination number with which ship-i, $j(\mathrm{k})$ can encounter a collision situation is $\mathrm{n} ! / \mathrm{k} !(\mathrm{n}-\mathrm{k})$ !. A total of 15 collision combination numbers are shown in Figure 2.

Table 2 shows 15 collision risk scenario-specific target ships, their initial/end speeds, and initial course information. Most of the scenarios are encountered in a crossing situation; however, in the case of scenario no.7, involving ship- 2 and ship-4, and scenario no.13, where ship- 4 and ship- 5 meet, the ships encounter a head-on situation. Moreover, in the case of scenario no.8, involving ship-2 and ship-5, and in scenario no. 15 , with ship-5 and ship-6, ship- 5 overtakes at the sterns of ship- 2 and ship- 6 .

Table 2. Scenario combinations for target ships under near-collision situations in Busan Port VTS area during time 05:33:05-05:53:35.

\begin{tabular}{ccccc}
\hline \multirow{2}{*}{ Scenario No. } & $\begin{array}{c}\text { Target Ships } \\
\text { (ship-i, ship-j) }\end{array}$ & $\begin{array}{c}\text { Initial Speed } \\
{[\mathbf{k t s}]}\end{array}$ & $\begin{array}{c}\text { End Speed } \\
{[\mathbf{k t s}]}\end{array}$ & $\begin{array}{c}\text { Initial Course } \\
{\left[{ }^{\circ}\right]}\end{array}$ \\
\hline no.1 & ship-1, ship-2 & 11,14 & 8,11 & 324,322 \\
no.2 & ship-1, ship-3 & 11,4 & 8,4 & 324,209 \\
no.3 & ship-1, ship-4 & 11,14 & 8,15 & 324,116 \\
no.4 & ship-1, ship-5 & 11,15 & 8,10 & 324,311 \\
no.5 & ship-1, ship-6 & 11,11 & 8,9 & 324,318 \\
\hline no.6 & ship-2, ship-3 & 14,4 & 11,4 & 322,209 \\
no.7 & ship-2, ship-4 & 14,14 & 11,15 & 322,116 \\
no.8 & ship-2, ship-5 & 14,15 & 11,10 & 322,311 \\
no.9 & ship-2, ship-6 & 14,11 & 11,9 & 209,116 \\
\hline no.10 & ship-3, ship-4 & 4,14 & 4,15 & 209,311 \\
no.11 & ship-3, ship-5 & 4,15 & 4,10 & 209,318 \\
no.12 & ship-3, ship-6 & 4,11 & 4,9 & 116,311 \\
\hline no.13 & ship-4, ship-5 & 14,15 & 15,10 & 116,318 \\
\hline no.14 & ship-4, ship-6 & 14,11 & 15,9 & 311,318 \\
\hline no.15 & ship-5, ship-6 & 15,11 & 10,9 & \\
\hline
\end{tabular}


The separation distances and CoRI results for each encounter scenario are shown in Figure 3, and these results are used to perform a detailed analysis of the collision risk between the ships. Figure 3a shows the separation distances over the navigation time for scenarios 1-15, and it indicates that most of the scenarios are close to the minimum separation distance of $3 \mathrm{NM}$. In Figure 3b, the near-collision situation occurred sequentially along with scenario-1 (Figure 4a situation), scenario-6 (Figure 5a situation), and scenario-4 (Figure 6a situation). Figure $3 \mathrm{~b}$ represents the CoRI results for each scenario as well as a detailed analysis of risk-recognizable scenarios no.1, no.4, and no.6, which have a CoRI value of more than $50 \%[30,50]$.

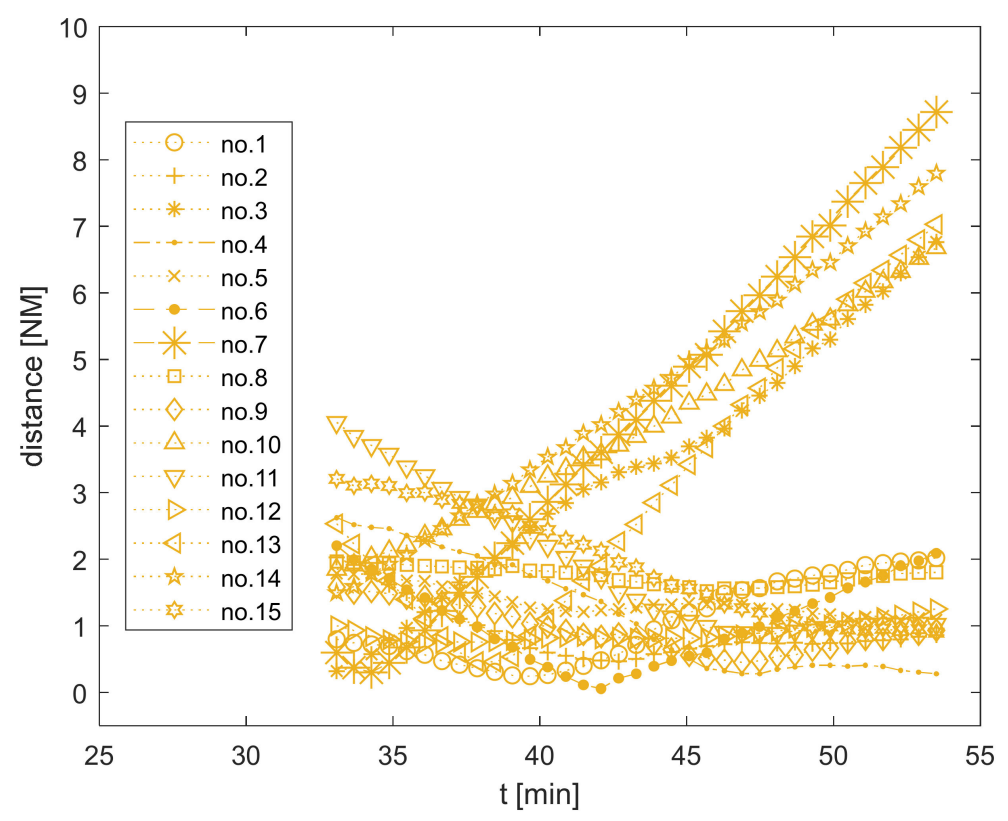

(a)

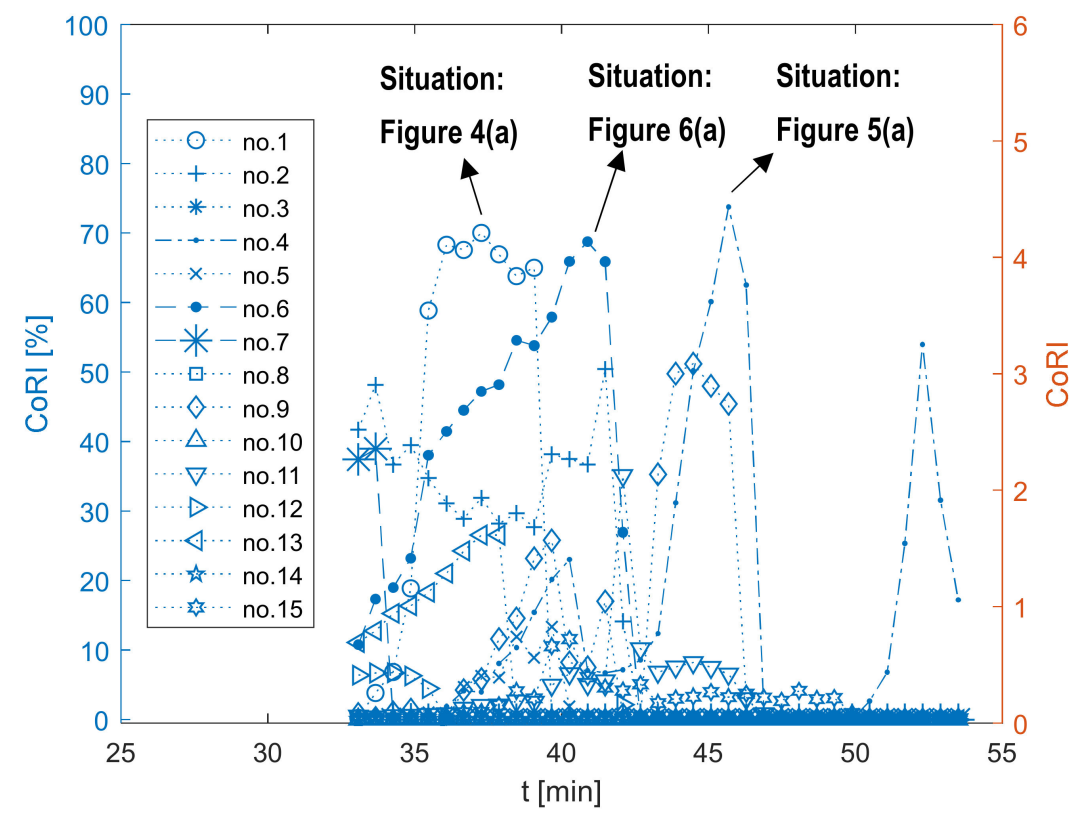

(b)

Figure 3. (a) Ship distance and (b) CoRI results by scenario no.: near-collision situation that occurred sequentially in scenario no.1-Figure 4a situation, no.6-Figure 6a situation, and no.4-Figure 5a situation. 


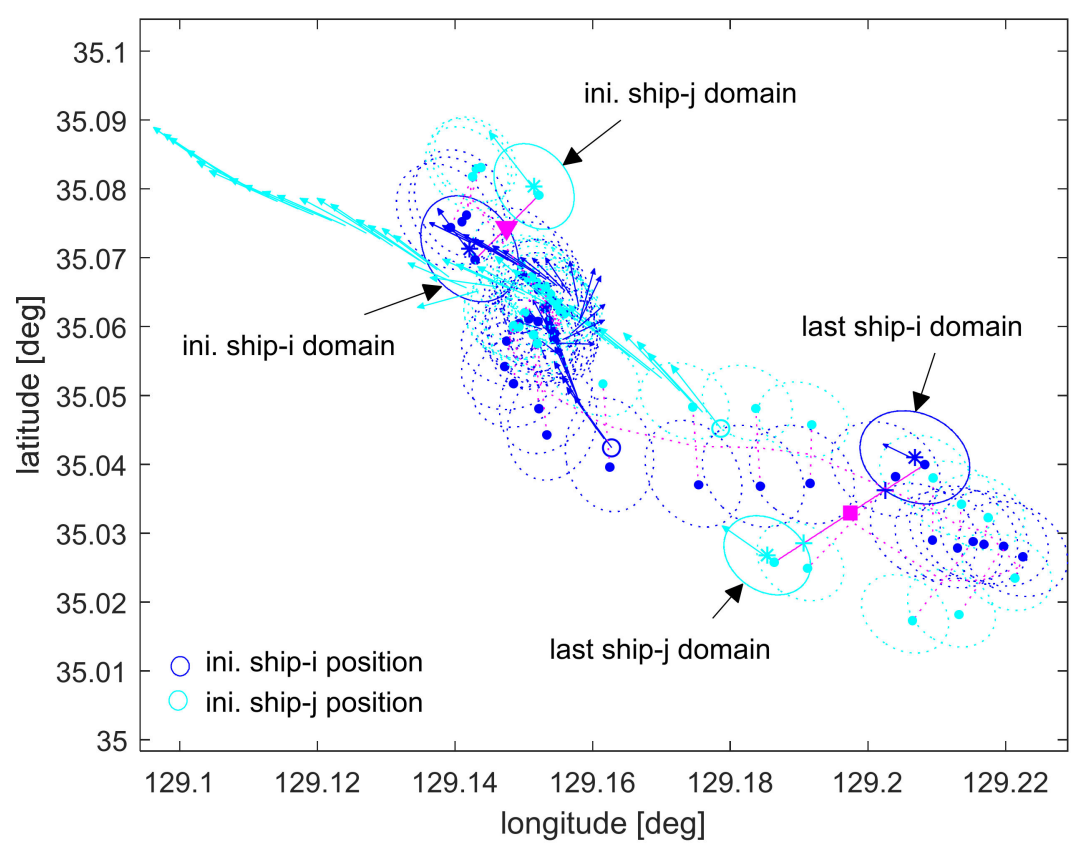

(a)

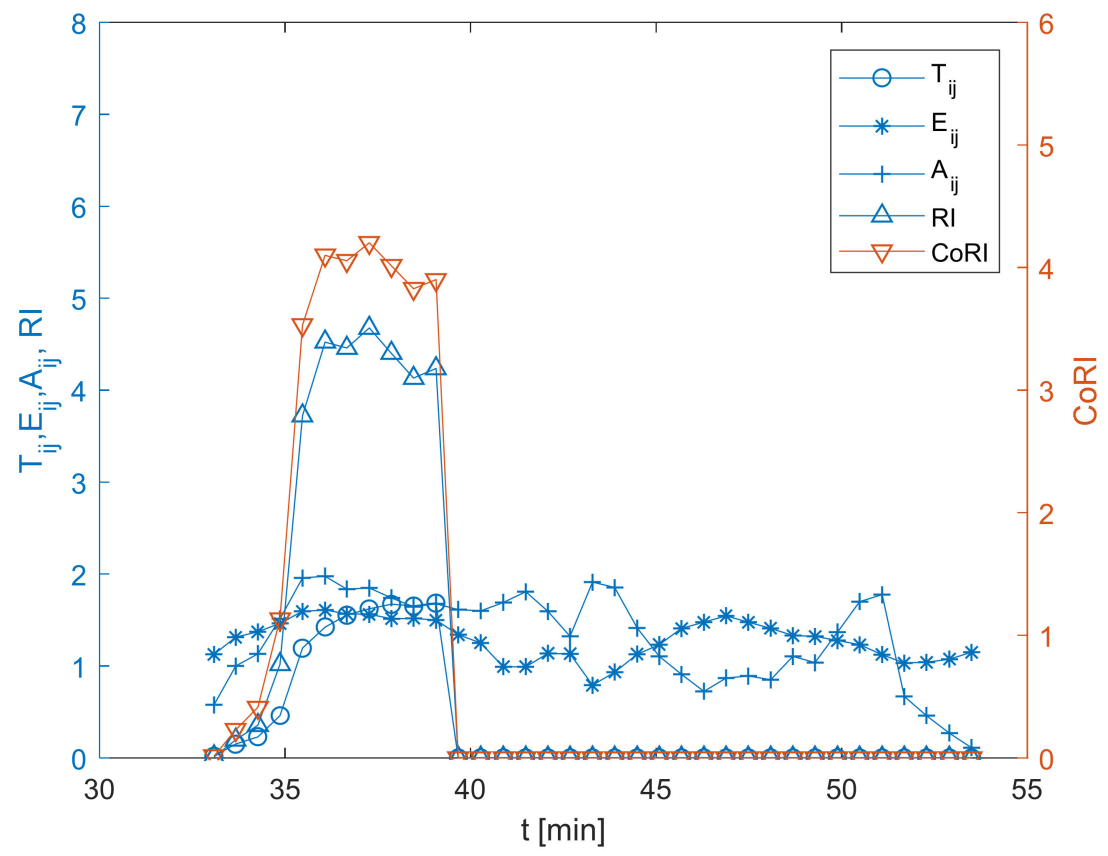

(b)

Figure 4. (a) Ship tracks with VTSO ship domain at CPA position $(\cdot$ CPA position, $\leftarrow:$-min vector); (b) CoRI results with T, E, and A indices of scenario no.1 (ship-i: ship-1, ship-j: ship-2). 


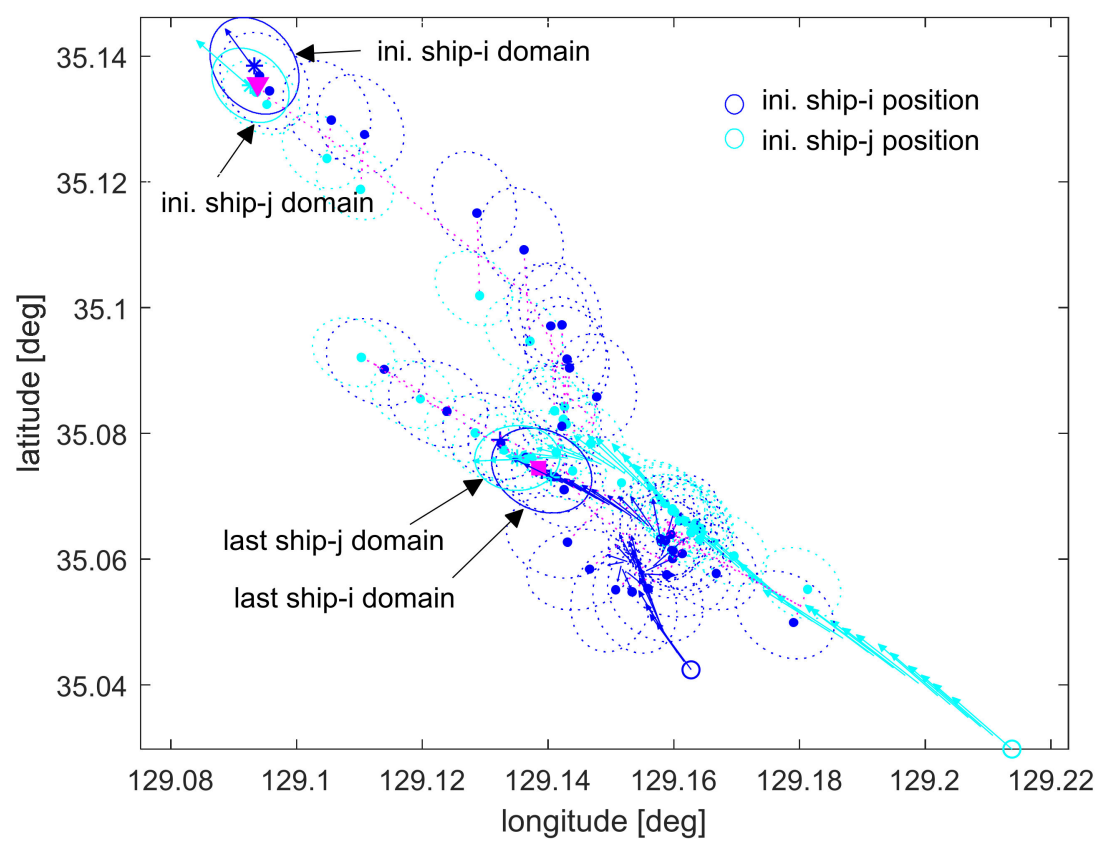

(a)

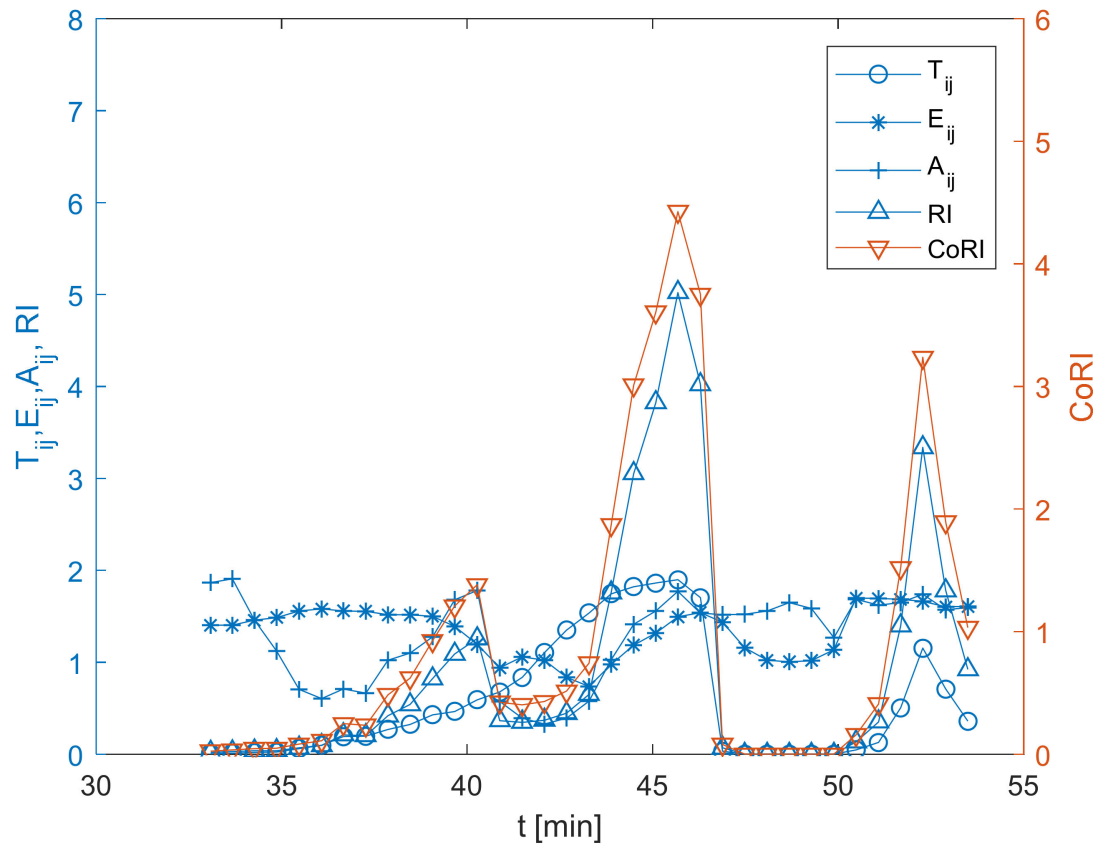

(b)

Figure 5. (a) Ship tracks with VTSO ship domain at CPA position ( $\because$ CPA position, $\leftarrow: 3$-min vector); (b) CoRI results with T, E, and A indices of scenario no.4 (ship-i: ship-1, ship-j: ship-5). 


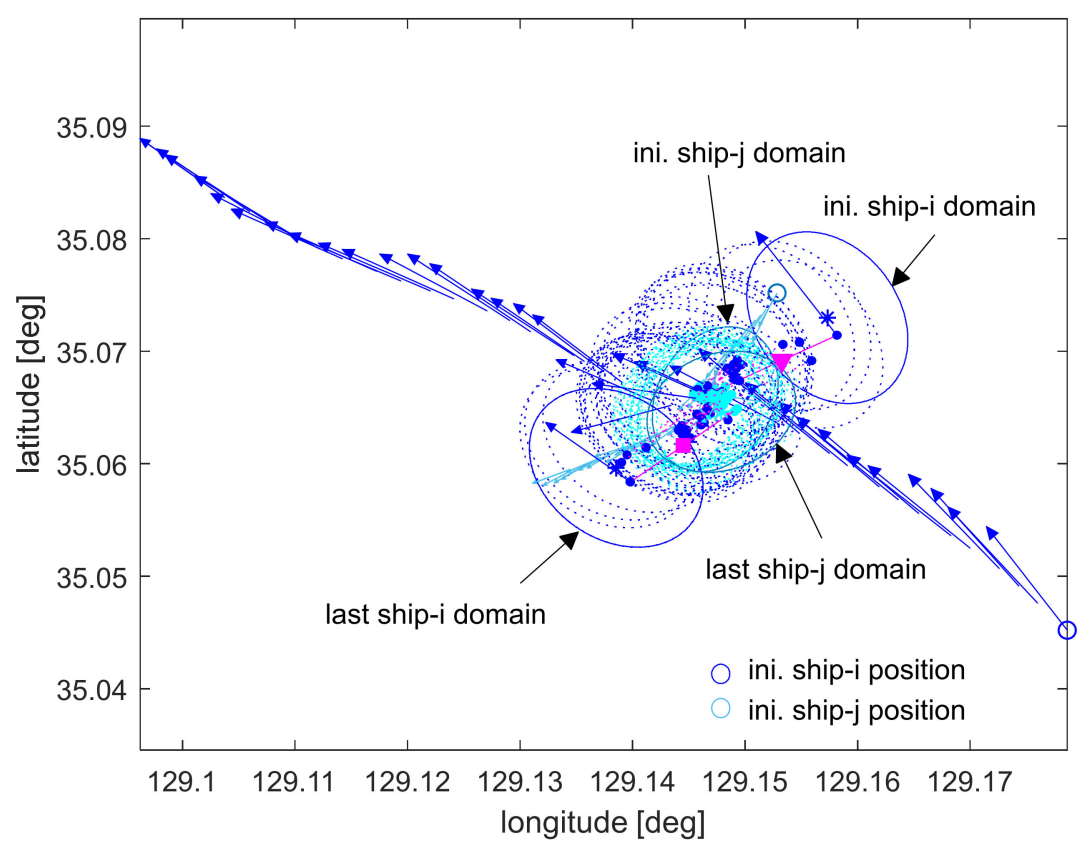

(a)

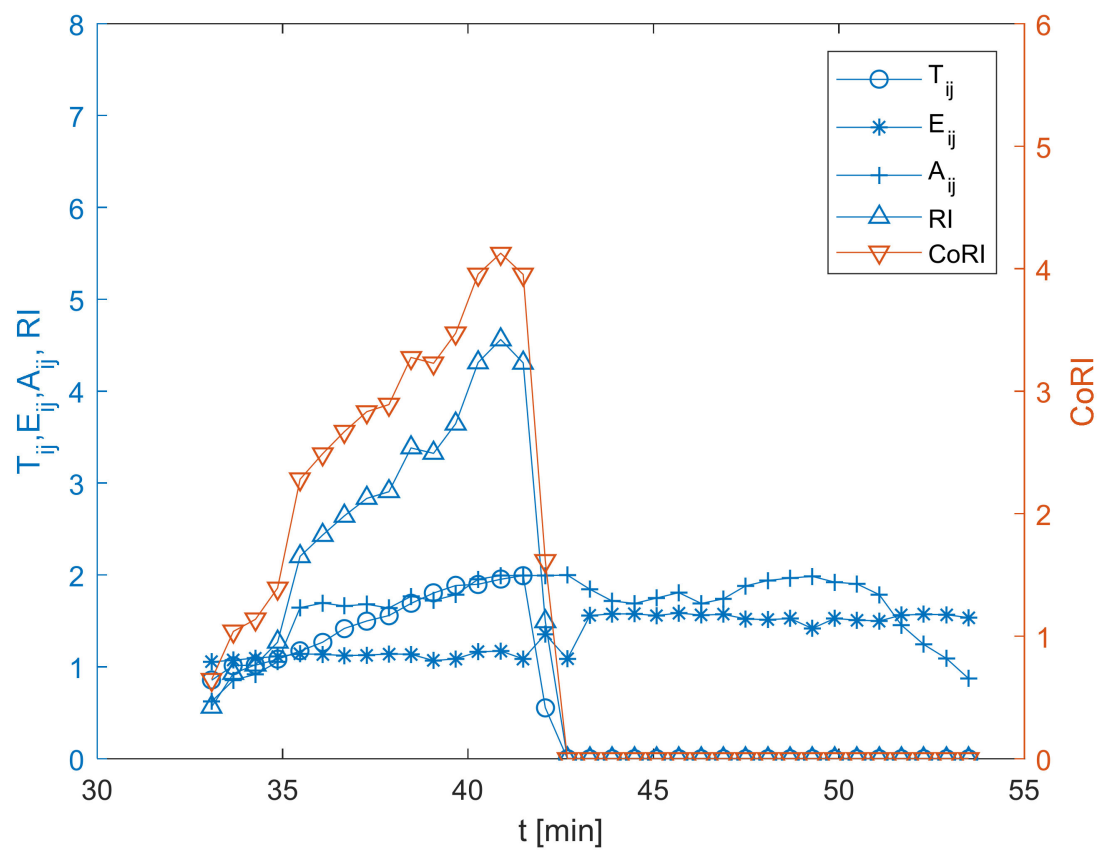

(b)

Figure 6. (a) Ship tracks with VTSO ship domain at CPA position ( $:$ CPA position, $\leftarrow:$ 3-min vector); (b) CoRI results with T, E, and A indices of scenario no.6 (ship-i: ship-2, ship-j: ship-3).

Figure 4 shows the results of the ship tracks and the CoRI results of scenario no.1 (ship$i$ : ship-1, ship-j: ship-2), and ship-j overtakes from the starboard side of the ship. From the analysis of the scenario along with other encounter ships, it was seen that ship- 1 changed its course to starboard to avoid ship-3, but, subsequently, ship-2 entering the Busan Port led to a collision risk situation. Then, ship-1 turned to the port side and avoided it owing to a collision risk with ship-2 entering the Busan Port. Figure 4 a plots the 3-min vector ship tracks of ship- $i, j$ with the VTSO ship domains at the CPA positions, and Figure $4 \mathrm{~b}$ 
plots the CoRI results over time with the T, E, and A indices. Figure $4 \mathrm{~b}$ shows that the CoRI also converges to zero as the $\mathrm{T}$ index converges to zero after $40 \mathrm{~min}$. A risk situation with a CoRI value of 50\% occurs from the starting point of the voyage to approximately $40 \mathrm{~min}$. At that time, it can be seen that the counter risk E increases in the case of a collision proximity situation, and it then turns to the port side and decreases again.

Figure 5 shows the ship track and CoRI results of scenario no.4 (ship-i: ship-1, ship-j: ship-5). As in scenario no.1, ship- $j$ overtakes from the right side of ship-i. Following the situation in Figure 4, ship-1 turned to the port side, followed by ship-2, and a dangerous situation occurred with ship- 5 entering the Busan Port. Then, ship- 1 slowed down after turning to the port side, and ship- 5 turned to the starboard and entered the Busan Port. Figure 5 a shows the 3 -min vector ship track results of ship- $i, j$ with the VTSO ship domains at the CPA positions, and Figure 5b plots the CoRI results over time using the T, E, and A indices. Figure $5 \mathrm{~b}$ shows the risk situation with a CoRI value of $50 \%$ between $43 \mathrm{~min}$ and $47 \mathrm{~min}$ from the start of the voyage and a collision risk situation with a risk of $50 \%$ or more near $52 \mathrm{~min}$. In addition, in the lower-risk interval, the $\mathrm{T}$ index also converges to zero. This indicates that, in Figure 5a, after ship- $i$ rotates around the course at approximately $40 \mathrm{~min}$, ship-j's navigation and the course become similar, which results in a risk of more than $50 \%$. In other words, after approximately $40 \mathrm{~min}$, ship- 1 turned to the port and avoided the collision situation with ship-5, and, thus, the encounter risk E decreased. At this time, the ship-to-ship proximity $\mathrm{T}$ according to the approach time decreased sharply owing to the deceleration of ship-1.

Figure 6 shows the ship track and CoRI results of scenario no.6 (ship-i: ship-2, ship-j: ship-3); ship-j crossed at the starboard of ship-i. After passing ship-1, ship-2 went through a dangerous situation with the tugboat ship- 3 crossing, and, at this time, it turned toward the port and entered the Busan Port from the bow of ship-3. Figure 6a shows the 3-min vector ship tracks of ship-i, $j$ with the VTSO ship domains at the CPA positions, and Figure $6 \mathrm{~b}$ plots the CoRI results over time using the T, E, and A indices. In Figure 6b, it is shown that the CoRI value gradually increases to more than $50 \%$ from the starting point of the voyage to approximately $42.5 \mathrm{~min}$, then converges to zero because the $\mathrm{T}$ index converges to zero after approximately $43 \mathrm{~min}$. This indicates that, in Figure 6a, ship-i clears the collision by turning its course at approximately $42.5 \mathrm{~min}$. In other words, the ship-to-ship proximity $\mathrm{T}$ according to the approach rapidly decreases as ship- 2 turns to the port side to avoid a collision situation.

Figure 7 shows the DCPA and TCPA for scenarios 1, 4, and 6 over time. From the DCPA results in Figure 7a, it can be observed that the DCPA is also close to 0.5 NM in the range where the risk of scenarios 1,4 , and 6 is higher than $50 \%$. In addition, the TCPA results in Figure $7 \mathrm{~b}$ show that the T index converges to zero in the interval where the TCPA is negative, which results in a low risk value. 


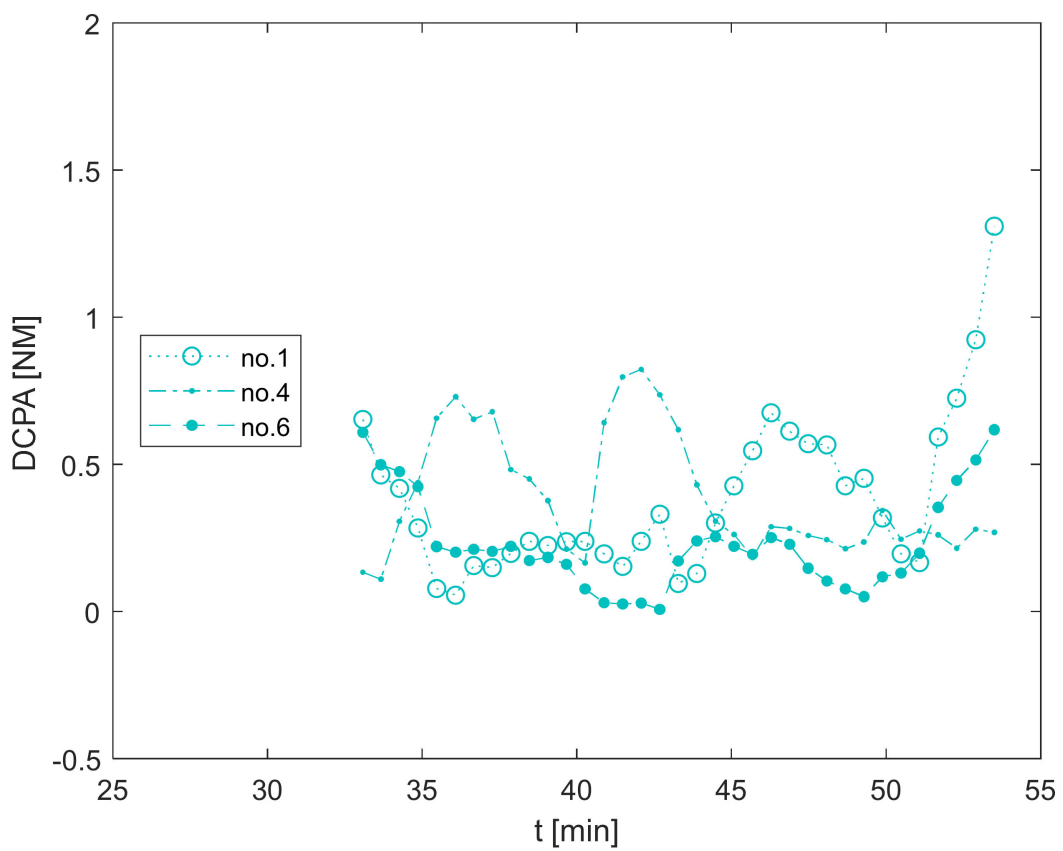

(a)

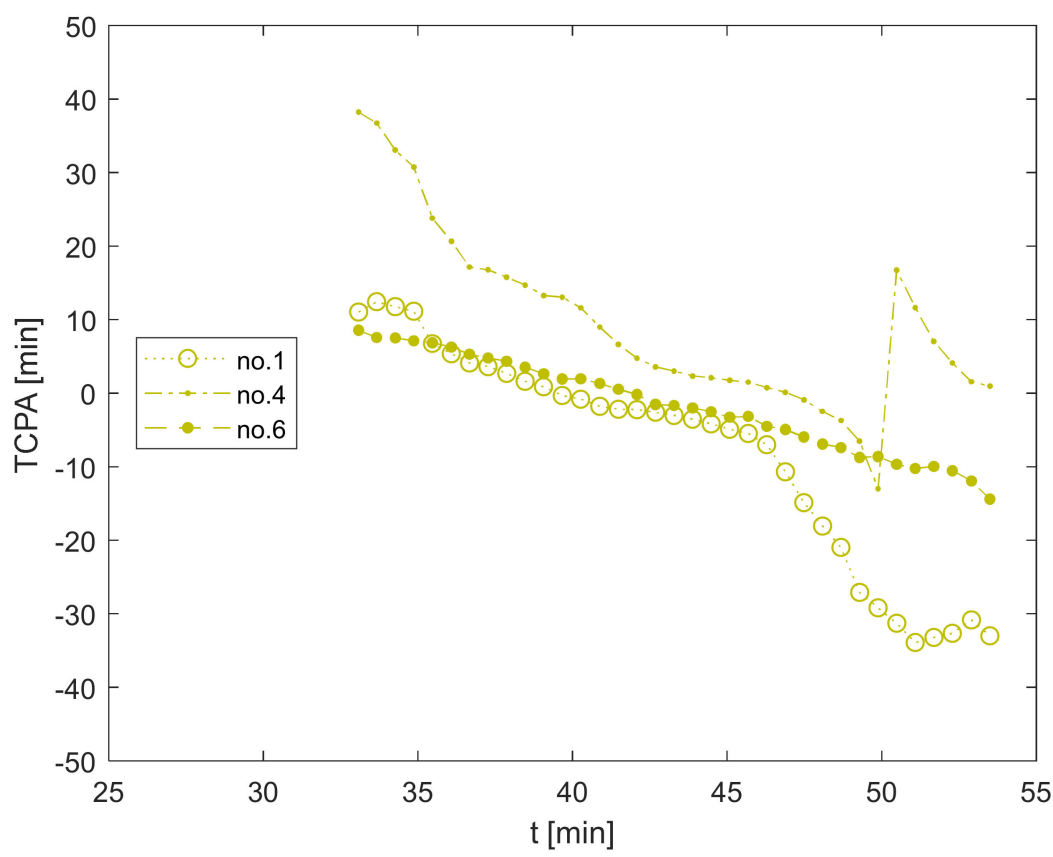

(b)

Figure 7. (a) DCPA and (b) TCPA of scenarios no.1 (ship-i: ship-1, ship-j: ship-2), no.4 (ship-i: ship-1, ship-j: ship-5), and no.6 (ship-i: ship-2, ship-j: ship-3).

\section{Collision Risk Assessment Support System}

\subsection{Collision Risk Assessment Algorithm}

The algorithm used to evaluate the collision risk between the ships in a multi-ship environment is shown in Algorithm 1. The following variables are used: the number of ship combinations, ship information (static and dynamic data), minimum separation distance between ships, and collision risk index using the CoRI model. 


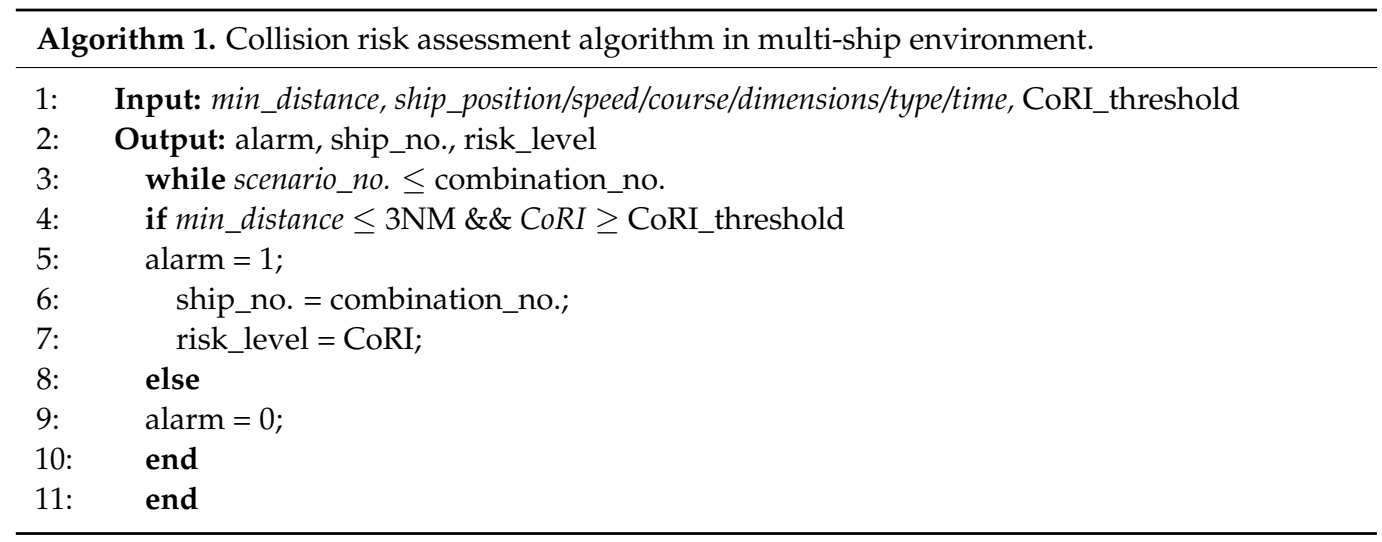

Algorithm 1 represents the procedure for the collision risk assessment algorithm and the input/output variables used in the collision risk assessment module at time $t$. The dynamic ship information is used as the input data. The min_dist represents the minimum distance between the vessels subject to the collision risk assessment (in nautical miles), the ship_position represents the latitude and longitude coordinates of the target ship- $i, j$, and the ship_speed represents the target ship- $i, j$ course. The ship static information, such as the ship_dimensions of ship-i,j and the ship_type, are also used. The time variable ship_time represents the computational time for the collision risk assessment, and the CoRI_threshold represents the threshold value, which is the CoRI safety reference value set by the VTSO and $\mathrm{RO}$ to evaluate the collision risk in the VTS and RC centers.

\subsection{System Configuration}

The system used to support the collision risk assessment in multi-ship environments expresses the collision risk index and ship-to-ship situation information and generates an alarm if the risk assessment index is above the threshold set by the VTSO and RO. At this time, the VTSO and RO can click on the alarm to check the ship's specifications and dynamic information along with the collision risk target ship-ID in the local waters to recommend the evacuation of the vessel and provide risk assessment information from the system, thus reducing or eliminating the risk of a collision.

A potential user interface of the collision RiASS, which supports the VTSO control and MASS RO remote control in a multi-ship environment, is shown in Figure 8.

When an alarm occurs in the collision risk assessment support system, the static information, such as the target ship type, dimensions (L: length, B: beam, D: drift) (m), and call sign, are expressed. In addition, the VTSO and RO can check the dynamic information at time $t(\mathrm{~s})$, such as speed (kts), separation distance between the ships (NM), DCPA (NM), and TCPA ( $\mathrm{min})$. The CoRI value is also displayed with the ship domain at the CPA position for an intuitive understanding of the ship-to-ship latitude and longitude coordinates (deg) in the local collision risk area. Additionally, the reference value for the alarm generation in the system was set at a risk of $50 \%$ or higher, and the CoRI value was set to 3 . 


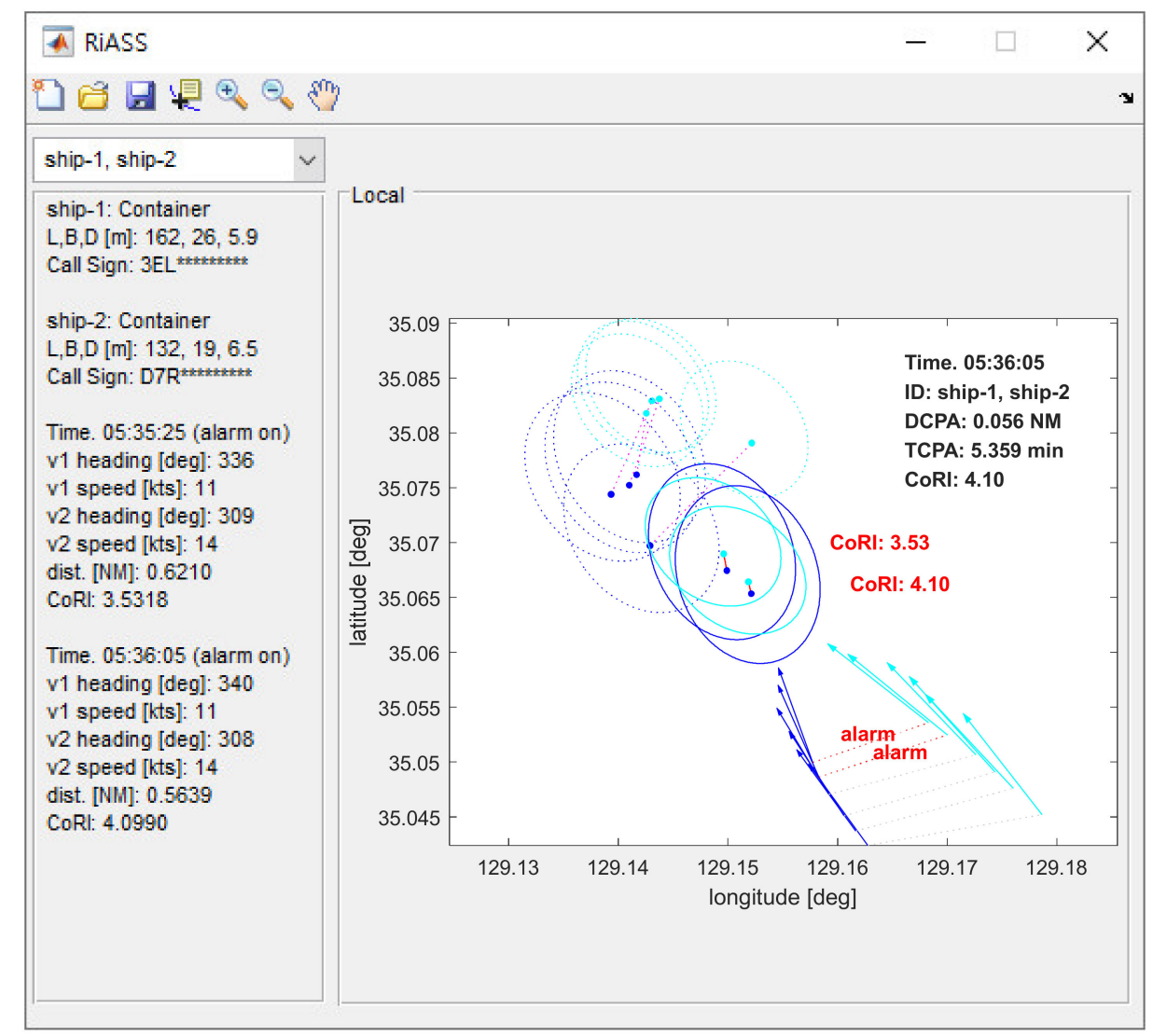

Figure 8. Collision risk assessment support system (RiASS) configuration.

\section{Discussion and Conclusions}

In this study, a collision risk assessment method and risk assessment support system were proposed to enhance the situational awareness of the VTSO and MASS RO in the event of a collision risk owing to an encounter between ships in a multi-ship environment in the VTS area.

The VTSO domain used in the risk assessment model is a ship domain that is statistically derived from the VTSO survey in the case of encounters between ships in coastal waters outside of the VTS area. The safety zone, which is the ship domain, applied in this study may have been larger than the safety zone of a waterway and anchorage in the VTS area of the port. In addition, there are limitations associated with this study: the risk analysis for near-collision scenarios at Busan Port did not reflect the unique characteristics of the port's environmental factors because the characteristics of each port are different.

The efficiency of the proposed collision RiASS was initially verified only at the system stage. Therefore, the effectiveness of future VTSOs and MASS ROs and their improved situational awareness of the local sea risk situation owing to the use of the proposed system has not yet been confirmed.

The limitations of the three near-collision scenarios analyzed in this study are that the CoRI model was applied to the collision risk situation at the VTS area of Busan Port and not all the collision risk situations at the VTS areas at other ports.

In summary, following discussions on the introduction of a MASS by the IMO, the IALA proposed the consideration of the "interaction between VTS and the control of MASSs" and the "sharing of situational awareness of the waterway within the VTS environment" when implementing a system to support MASS operations. Therefore, this study proposes a real-time collision RiASS that allows the VTSO and MASS RO to receive situational information on risk situations in local waters along with quantitative data when near-collision situations occur in the multi-ship environment of the VTS area. 
The risk evaluation of the RiASS system is based on the VTSO ship domain, which is a method used to predict possible collision risk situations in advance by moving the existing ship domain to the CPA location. It is a real-time CAS concept that generates an alarm if the risk value exceeds the safety standard set by the VTSO and MASS RO. To evaluate the validity of the proposed system, three near-collision-scenario risk analyses were performed at Busan Port. A risk assessment based on the ship encounter was conducted on all the possible combination cases of the risk assessment for a multi-ship environment. The changes in the TCPA, DCPA, and inter-ship distance were analyzed over time for three cases with a CoRI value of more than $50 \%$, which is a risk recognition stage. The analysis confirmed that the TCPA was lowered within 10 min and the DCPA within approximately 0.5 nautical miles. Additionally, the separation distance between the ships was lowered to within 3 nautical miles. This can improve the situational awareness of the VTSO and MASS RO through alert alarms in the event of a near-collision situation between multiple ships in the VTS area, and the validity of the real-time CAS is confirmed through the system.

In the future, further research is necessary on safety areas that reflect the characteristics of the waterways and anchorages in ports, and the environment of each VTS area must be considered. In addition, in this paper, although the risk attitude of the VTSO was equally applied to the $\mathrm{RO}$, a study on the RO's attitude on the risk (or situation awareness) is necessary when the MASS vessel is operated later.

Author Contributions: Conceptualization and methodology, Y.Y.; survey and analysis, Y.Y.; writingoriginal draft preparation, Y.Y.; writing - review and editing, Y.Y.; supervision and project administration, J.-S.L. All authors have read and agreed to the published version of the manuscript.

Funding: This research was supported by "The Development of Ship Collision Risk and Traffic Safety Evaluation Model through the Situation Awareness Analysis of VTSOs (NRF-2019R1G1A1008299)" funded by the National Research Foundation of Korea (NRF) and the "Development of Autonomous Ship Technology (20200615)" funded by the Ministry of Oceans and Fisheries (MOF, Korea).

Institutional Review Board Statement: Not applicable.

Informed Consent Statement: Not applicable.

Data Availability Statement: Request to corresponding author of this article.

Conflicts of Interest: The authors declare no conflict of interest.

\section{References}

1. IMO. Regulatory Scoping Exercise for the Use of Maritime Autonomous Surface Ships (MASS)—Comments on the Regulatory Scoping Exercise; MSC 99/5; International Maritime Organization: London, UK, 2018.

2. IMO. Regulatory Scoping Exercise for the Use of Maritime Autonomous Surface Ships (MASS)—Recommendations on Identification of Potential Amendments to Existing IMO Instruments; MSC 99/5/3; International Maritime Organization: London, UK, 2018.

3. IMO. Regulatory Scoping Exercise for the Use of Maritime Autonomous Surface Ships (MASS)_Considerations on and Proposals for the Methodology to Use Within the Framework of the Regulatory Scoping Exercise; MSC 99/5/4; International Maritime Organization: London, UK, 2018.

4. IMO. Regulatory Scoping Exercise for the Use of Maritime Autonomous Surface Ships (MASS)—Considerations on Definitions for Levels and Concepts of Autonomy; MSC 99/5/6; International Maritime Organization: London, UK, 2018.

5. IMO. Regulatory Scoping Exercise for the Use of Maritime Autonomous Surface Ships (MASS)_Japan's Perspective on Regulatory Scoping Exercise for the Use of MASS; MSC 99/5/9; International Maritime Organization: London, UK, 2018.

6. IMO. Regulatory Scoping Exercise for the Use of Maritime Autonomous Surface Ships (MASS)—Comments on Documents MSC 99/5, MSC 99/5/2, MSC 99/5/5, MSC 99/5/8 and MSC 99/5/9; MSC 99/5/11; International Maritime Organization: London, UK, 2018.

7. IMO. Interim Guidelines for MASS Trials; MSC.1/Circ.1604; International Maritime Organization: London, UK, 2019.

8. IALA. IALA Guideline on Developments in Maritime Autonomous Surface Ships; ENAV27-8.1.2; International Association of Marine Aids to Navigation and Lighthouse Authorities: Paris, France, 2021.

9. Chauvin, C.; Lardjane, S.; Morel, G.; Clostermann, J.-P.; Langard, B. Human and organisational factors in maritime accidents: Analysis of collisions at sea using the HFACS. Accid. Anal. Prev. 2013, 59, 26-37. [CrossRef]

10. Gale, H.; Patraiko, D. Improving navigational safety. Seaways 2007, 4-8.

11. Grech, M.; Horberry, T.; Smith, A. Human error in maritime operations: Analyses of accident reports using the leximancer tool. In Proceedings of the 4th Annual Meeting of the Human Factors and Ergonomics Society, Baltimore, MD, USA, 30 September-4 October 2002. 
12. Hetherington, C.; Flin, R.; Mearns, K. Safety in shipping: The human element. J. Saf. Res. 2006, 37, 401-411. [CrossRef] [PubMed]

13. Rothblum, A. Human error and maritime safety. In Proceedings of the Maritime Human Factors Conference, Linthicum, MD, USA, 13-14 March 2000.

14. Wagenaar, W.A.; Groeneweg, J. Accidents at sea: Multiple causes and impossible consequences. Int. J. Man-Mach. Stud. 1987, 27, 587-598. [CrossRef]

15. Fuji, J.; Tanaka, K. Traffic capacity. J. Navig. 1971, 24, 543-552. [CrossRef]

16. Coldwell, T.G. Marine traffic behaviour in restricted waters. J. Navig. 1983, 36, 431-444. [CrossRef]

17. Goodwin, E.M. A statistical study of ship domains. J. Navig. 1975, 28, 328-344. [CrossRef]

18. Hansen, M.G.; Jensen, T.K.; Lehn-Schiøler, T.; Melchild, K.; Rasmussen, F.M.; Ennemark, F. Empirical ship domain based on AIS data. J. Navig. 2013, 66, 931-940. [CrossRef]

19. Wang, Y.; Chin, H.C. An empirically-calibrated ship domain as a safety criterion for navigation in confined waters. J. Navig. 2016, 69, 257-276. [CrossRef]

20. Davis, P.V.; Dove, M.J.; Stockel, C.T. A computer simulation of marine traffic using domains and arenas. J. Navig. 1980, 33, 215-222. [CrossRef]

21. Davis, P.V.; Dove, M.J.; Stockel, C.T. A computer simulation of multi-ship encounters. J. Navig. 1982, 35, 347-352. [CrossRef]

22. Dinh, G.H.; Im, N. The combination of analytical and statistical method to define polygonal ship domain and reflect human experiences in estimating dangerous area. Int. J. e-Navig. Mar. Econ. 2016, 4, 97-108. [CrossRef]

23. Liu, J.; Zhou, F.; Li, Z.; Wang, M.; Liu, R.W. Dynamic ship domain models for capacity analysis of restricted water channels. J. Navig. 2016, 69, 481-503. [CrossRef]

24. Pietrzykowski, Z. Ship's fuzzy domain-A criterion for navigational safety in narrow fairways. J. Navig. 2008, 61, 499-514. [CrossRef]

25. Pietrzykowski, Z.; Uriasz, J. The ship domain-A criterion of navigational safety assessment in an open sea area. J. Navig. 2009, 62, 93-108. [CrossRef]

26. Wang, N.; Meng, X.; Xu, Q.; Wang, Z. An intelligent spatial collision risk based on the quaternion ship domain. J. Navig. 2010, 63, 733-749. [CrossRef]

27. Wang, N. A novel analytical framework for dynamic quaternion ship domains. J. Navig. 2013, 66, 265-281. [CrossRef]

28. Zhu, X.; Xu, H.; Liu, J. Domain and its model based on neural networks. J. Navig. 2001, 54, 97-103. [CrossRef]

29. Westrenen, F.; Baldauf, M. Improving conflicts detection in maritime traffic: Case studies on the effect of traffic complexity on ship collisions. Proc. IMechE Part M J. Eng. Marit. Environ. 2020, 234, 209-222. [CrossRef]

30. Yoo, Y.; Lee, J.-S. Evaluation of ship collision risk assessments using environmental stress and collision risk models. Ocean Eng. 2019, 191, 1-13. [CrossRef]

31. Lehikoinen, A.; Hanninen, M.; Storgard, J.; Luoma, E.; Mantyniemi, S.; Kuikka, S. A Bayesian Network for Assessing the Collision Induced Risk of an Oil Spill in the Gulf of Finland. Environ. Sci. Technol. 2015, 49, 5301-5309. [CrossRef]

32. Goerlandt, F.; Montewka, J.; Kuzmin, V.; Kujala, P. A risk-informed ship collision alert system: Framework and application. Saf. Sci. 2015, 77, 182-204. [CrossRef]

33. Chin, H.-C.; Debnath, A.K. Modeling perceived collision risk in port water navigation. Saf. Sci. 2009, 47, 1410-1416. [CrossRef]

34. Goerlandt, F; Kujala, P. On the reliability and validity of ship-ship collision risk analysis in light of different perspectives on risk. Saf. Sci. 2014, 62, 348-365. [CrossRef]

35. Goerlandt, F.; Montewka, J. A Framework for Risk Analysis of Maritime Transportation Sytems: A Case Study for Oil Spill from Tankers in a Ship-Ship Collision. Saf. Sci. 2015, 76, 42-66. [CrossRef]

36. Goerlandt, F.; Montewka, J. Maritime Transportation Risk Analysis: Review and Analysis in Light of Some Foundational Issues. Reliab. Eng. Syst. Saf. 2015, 138, 115-134. [CrossRef]

37. Patraiko, D.; Wake, P.; Weintrit, A. e-Navigation and the human element. TransNav-Int. J. Mar. Navig. Saf. Sea Transp. 2010, 4, 11-16.

38. Hilgert, H.; Baldauf, M. A common risk model for the assessment of encounter situations on board ships. Dtsch. Hydrogr. Z. 1997, 49, 531-542. [CrossRef]

39. Baldauf, M.; Benedict, K.; Fischer, S.; Motz, F.; Schroder-Hinrichs, J.-U. Collision avoidance systems in air and maritime traffic. Proc. Inst. Mech. Eng. Part O J. Risk Reliab. 2011, 225, 333-343. [CrossRef]

40. Bukhari, A.C.; Tusseyeva, I.; Lee, B.-G.; Kim, Y.-G. An intelligent real-time multi-vessel collision risk assessment system from VTS view point based on fuzzy inference system. Expert Syst. Appl. 2013, 40, 1220-1230. [CrossRef]

41. Kao, S.-L.; Lee, K.-T.; Chang, K.-Y.; Ko, M.-D. A fuzzy logic method for collision avoidance in Vessel Traffic Service. J. Navig. 2007, 60, 17-31. [CrossRef]

42. Ren, Y.; Mou, J.; Yan, Q.; Zhang, F. Study on assessing dynamic risk of ship collision. In Multimodal Approach to Sustained Transportation System Development: Information, Technology, Implementation; Presented at the International Conference on Transportation Information and Safety; ASCE: Wuhan, China, 2011; pp. 2751-2757.

43. Mou, J.M.; van der Tak, C.; Ligteringen, H. Study on collision avoidance in busy waterways by using AIS data. Ocean Eng. 2010, 37, 483-490. [CrossRef]

44. Baldauf, M.; Fischer, S. Merging conventionally navigating ships and MASS-Merging VTS, FOC and SCC? TransNav 2019, 13, 495-501. [CrossRef] 
45. Cockcroft, A.N.; Lameijer, J.N.F. A Guide to the Collision Avoidance Rules: International Regulations for Preventing Collisions at Sea, 7th ed.; Elsevier: Croydon, UK, 2011; p. 108.

46. IMO. International Regulations for Preventing Collisions at Sea; International Maritime Organization: London, UK, 1972.

47. Lee, J.-S.; Song, C.-U. The situation awareness analysis of VTSOs in the close quarters situation. J. Navig. Port Res. 2018, 42, 25-30.

48. KCG. Vessel Traffic Service System Configuration. Korea Coast Guard. Available online: http://www.kcg.go.kr/kcg/si/sub/ info.do?page $=2843 \& \mathrm{mi}=2843 /$ (accessed on 12 September 2021).

49. KCG. Guide to Vessel Traffic Service 2020. Korea Coast Guard. Available online: http://www.kcg.go.kr/kcg/na/ntt/ selectNttInfo.do?nttSn=23295/ (accessed on 12 September 2021).

50. Inoue, K. Evaluation method of ship-handling difficulty for navigation in restricted and congested waterways. J. Navig. 2000, 53, 167-180. [CrossRef] 